\title{
Investment and construction project matrix as the basis of forming the highly effective organizational structure
}

\author{
Andrey Morozenko ${ }^{1, *}$ \\ ${ }^{1}$ Moscow State University of Civil Engineering, Yaroslavskoe shosse, 26, Moscow, 129337, Russia
}

\begin{abstract}
The article covers the research results of the ways of forming the effective organizational structure for investment and construction project based on key events matrix. Current practice of investment and construction project development does not provide for project organizational structure detailed formation. Construction management plan (CMP) describes the organizational structure relatively and in general terms. Therefore, the customer confines himself only to development of staff's schedule, and delegating the formation of organizational structure to the general contractor, what is moving the solution of this task to the construction site. A large number of participants form a spontaneous organizational structure, so the management of this structure becomes manual. This leads to the numerous adjustments to plans and construction schedules, as well as additions and changes in the technical documentation of the project. All this result in unstable work, unreasonable delays and, eventually, in quality deterioration, disruption of deadlines and rise in construction costs. This article describes the method of forming the highly effective investment and construction project's organizational structure, which is based on the key events matrix that is the network functional model of project's executive system. Its properties, transformation rules and the forming algorithm are described in details.
\end{abstract}

\section{Introduction}

The necessity of developing the highly effective organizational structures of investment and construction projects is based on a number of unsolved problems in construction industry. Despite the impressive examples of massive structure constructions in Vladivostok, Sochi, Kerch and Jamal their erection had some problems and difficulties that are typical for the industry. Current construction practice constantly encounters system problems, which reduce the efficiency of construction organizations and, thus, of the whole industry as well. Analytics identify a whole list of problems: financial, juridical, personnel, technological. We consider the issue of highly effective organizational structure's formation of investment and construction project, which is provided with such competitive qualities as flexibility, stableness, safety. One of these structures is the reflex-adaptive structure of investment and

* Corresponding author: morozenkoaa@mgsu.ru 
construction project [1,2], which consists of a set of functional blocks. This blocks form the executive system of organizational structure and of management system, which organizes production and logical links of functional blocks in the process of project's implementation, as well as their interaction in time according to technological process executive program throughout the project's life cycle.

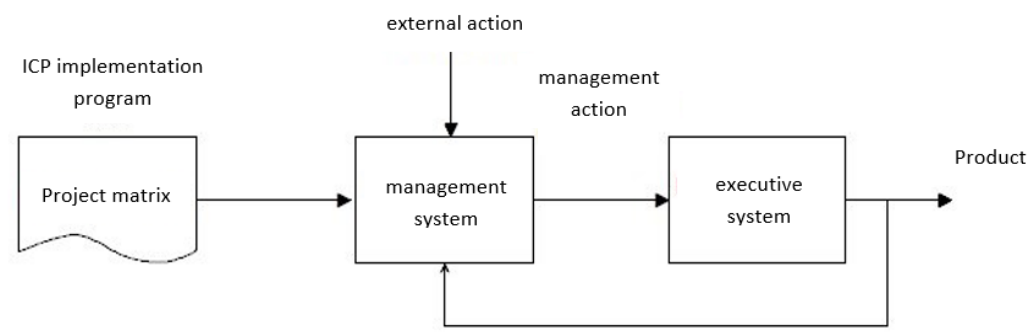

Fig. 1. Enlarged scheme of stream-oriented links of investment and construction project system.

The scheme of stream-oriented links of investment and construction project system (Figure 1) illustrate three main parts of investment and construction project. Their functions are:

Executive system is the physical implementer of operational processes at all stages of ICP construction cycle. It consists of functional blocks complex, which includes production units united by the similar type of works. Links structure of these blocks changes according to investment and construction project's implementation phases and stages.

Management system is the analytical block, which produce control actions based on building program, consider changes of the environment and ensuring the compliance of executive system's work results with program requirements.

Project matrix is the program of investment and construction project implementation. It is developed based on key events of construction technological process, which is stated in construction management plan and construction execution plan (CEP).

Mostly, project's organizational structure is based on staff's schedule, list of job descriptions and senior executives' assignment to structural subdivisions of investment and construction project.

Each ICP component has its own design features, which are analyzed in the whole range of works [3-9]. In this article we consider the project matrix in detail, the specific of its formation, main methods of organizational structure project design based on key events matrix.

Features and characteristic of planned works determine organizational structure of investment and construction project. In fact, the project organizational structure formation starts with pre-project works that form the construction's technical documentation.

If the project is carried out as the full life cycle form, then this is preceded by the formation of "zero" stage of structure implementation, when the project does not operate with the construction industry structure, but develop purpose performances and project's performance figures.

Nowadays domestic practice of large-scale projects implementation suggests the involvement of a large number of contracting organization. Despite the significant number of project's participants construction documentation does not define project organizational 
architecture, not to mention the optimal number of interaction during the project implementation. The inclusion of construction management plan and construction execution plan in technical documentation, which is required by the law, does not contain any instructions considering creation of any organizational structure.

In addition, CEP focuses on technological aspects of construction installation works (CIW): layout and location plan, the manpower and machinery requirement estimation, progress schedule and etc. All organizational design components are presented in CMP, but it describes only one phase of the life cycle - construction and installation works (CIW). Even CIW does not clearly exemplify mutual interactions between contractors and their units on construction site of facility. To some extent, this can be tolerated while building a simple standard construction, where the only one phase is realized - construction and installation works, where the developer functions are delegated to the general contractor by the customer, who, in fact, forms the organizational structure according to his own understandings and interests.

The absence of a well-defined project organizational structure, which adapts to each current project phase, forces construction organizers to switch to "manual control", when the current issues of contractors activities associativity moves to the construction site.

An unnecessary rush is created, erroneous decisions are made, that creates a void in work organization, alterations, adjustments and changes, unreasonable delays and fast catching up of lagging works.

The struggle against these insufficiencies for the efficiency of the construction industry forces construction organizers and the national scientific school to intensively study all aspects of the construction industry and to entrench the knowledge and competency that are gained during this process.

The research, which is being conducted in MGSU, allowed revealing new ways of further improvement of the investment and construction project organizational structure. These researches are based on the information paradigm of the project organizational structure formation. The key to project's reliability, durability and stability lies in the depth of the organizational structure and construction documentation development process. The main problems lie in the inability to effectively organize and manage the development of projects.

This article considers several aspects that facilitate a solution to this problem. Earlier it was noted that the current technical documentation package for the investment and construction project's implementation does not contain a detailed description of its organizational structure. Considering phase and gradual character of changes in project participants' interaction order, i.e. a constant change of the actual organizational structure, management and control process weakens and, as a result, it decreases all project's and final product's parameters. This system error is assumed to be eliminated by offered method of organizational structure design that based on a key events matrix.

Basically, the key events matrix is a functional model of the executive system organizational structure of the investment and construction project. It can have a form of a network diagram or an oriented graph, wherein the vertices display events in the project life-cycle, and the arcs - the logical link of these events and their sequence. This graph is also represents by model of functional blocks logical links at all project life cycle stages, which definitively determines its organizational structure. The project matrix can be considered as a graphical representation of the program that implements the management system in order to provide the appropriate organizational structure in each phase of the investment and construction project. The division of construction works complex into technological and logical components provides an opportunity to separate issues of participants organizational interaction into the optimal organizational structure that fully complies with the character, volume and features of the structures. 
All properties of network models can be refer to the properties of the matrix. In our case, "scaling" and "stitching" features of a network structure are the most important. Depending on the amount of future work, the matrix can be single- or multi-level. Matrix levels are correlated with the construction management plan and the construction execution plan accordingly. Matrix key events of different levels have identical characteristics and serve as critical points within verification of matrix and programs compiling .

Introducing the concept of a key event, we define it as the result of a certain work action. In technical meaning, we define the event as the result of the technological operation execution. Let us introduce the necessary events differentiation: the result of an elementary operation execution is an elementary event, the result of a technological process operation is an operational event or for short an event, and a set of event results forms a key event. As a reminder, an operation is a technologically consistent and organizationally indivisible element of the construction process.

From the production point of view, event is the completion of any work or its part that is determined by technical documentation and lead to a certain material result. From a system point of view, considering the work organization's network model, event is a graph vertex that describe work coordination and sequence, and therefore a structure of a specific project execution phase. The main difference between events is the number of inlinks order. The event with the maximal inlink order will be defined as a key event. A key event or a series of them completes the phase or stage of project implementation, forms a new one or alters the previous organizational structure into the organizational structure of a new construction phase.

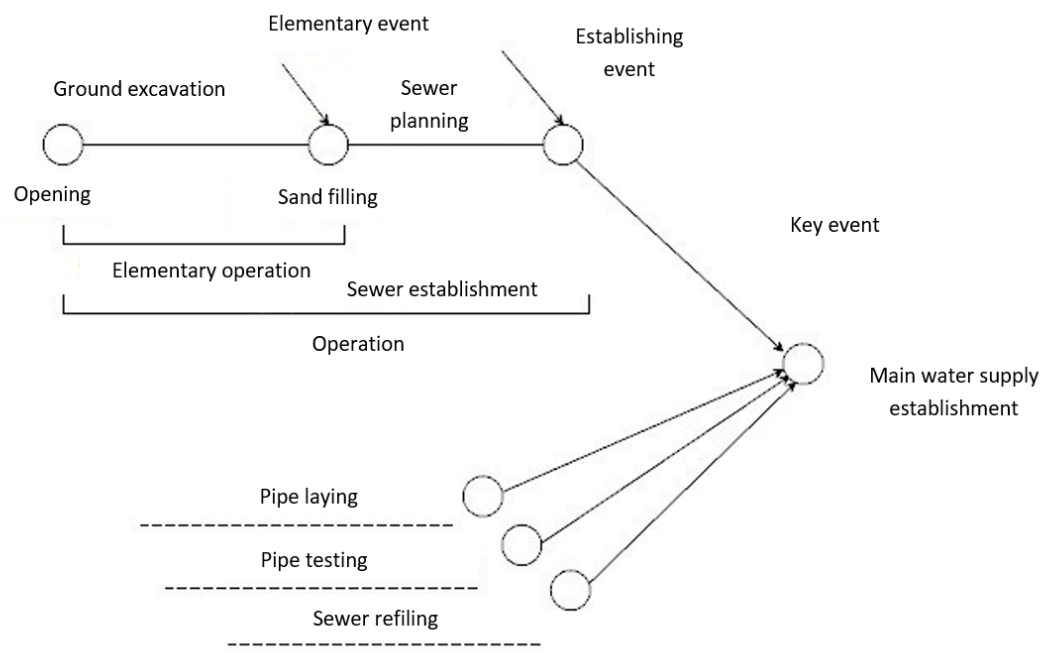

Fig. 2. Key event determination scheme

The diagram presented in Figure 3 requires some interpretation. Firstly, we emphasize once again that the organizational structure designing is just as the same phase as the object or its systems design. Therefore, this work should be handled by a specialist or a group of specialists called system designers [10]. It is analogous with IT systems, where are software engineers and system programmers. Organizational structure formation of large-scale construction requires of developers a large theoretical knowledge and sufficient practical experience in order to fully understand the logic of construction, to properly divide the technological process into operational and logical connections, to prepare clear and understandable construction documentation for contractors. Secondly, it is necessary to 
understand that the main support complex in project matrix formation are not works, but events. The matrix reflects the events implementation through the certain works execution. For this reason, all designers' attention should be focused on the accuracy of events sequence and their logical interconnections. Matrices of the same project can be formed in different scales, but it is more efficient to develop a matrix from a large scale to an extremely small one with a specified events detalization.

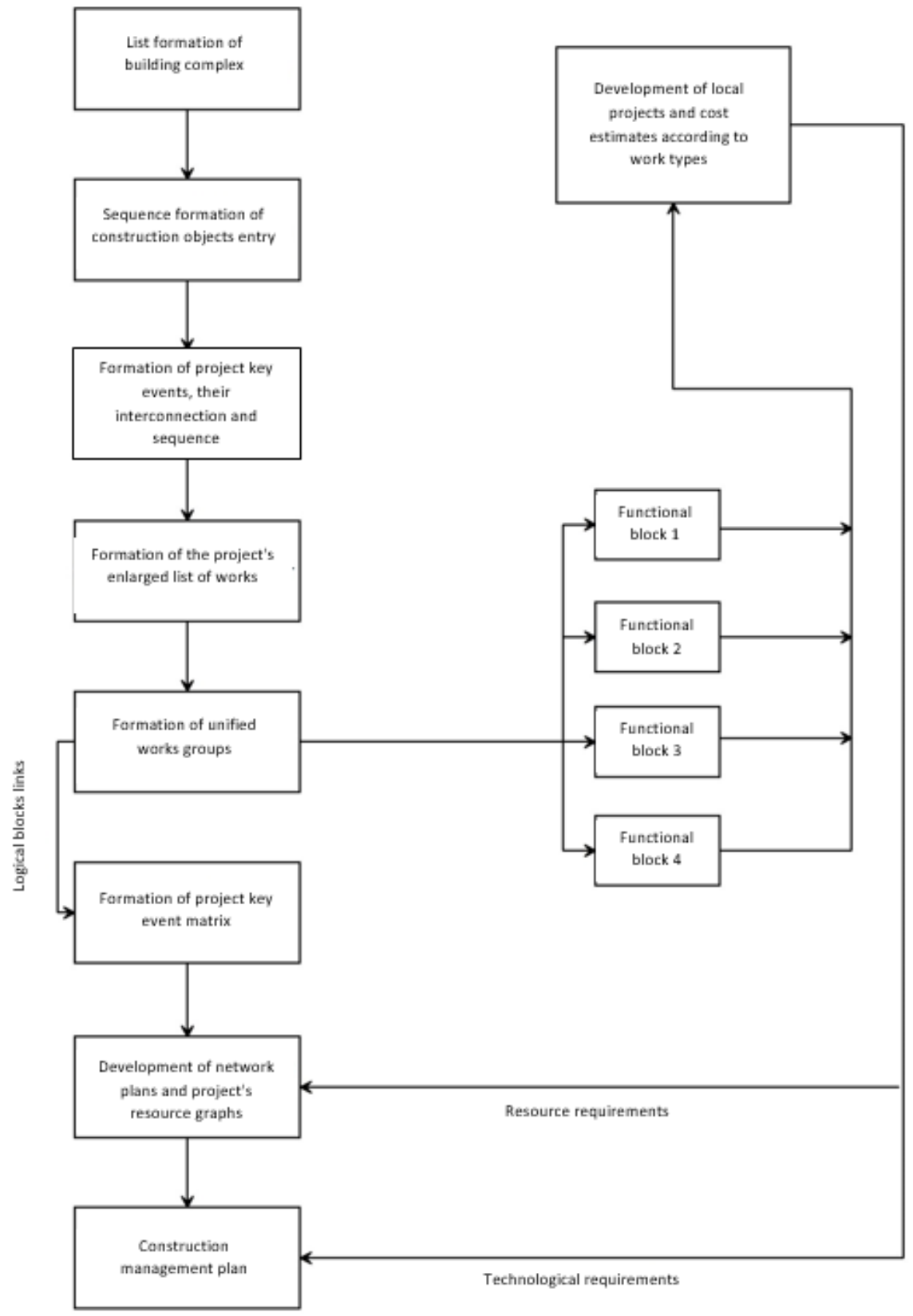

Fig. 3. Works block-scheme of key events matrix formation of the investment and construction project. 
The designing process of investment and construction project's organizational structure decisively influence on the quality, timing, and ICP's implementation economy in whole. To accomplish this task, it is necessary to develop all construction documentation in detail. In fact, it is necessary to create a functional dynamic model of the project in the digital virtual space with a powerful suite of display systems. This allows system operator before the development of the construction site to know when and where the construction brigade will be directed, where each cube of concrete will be distributed, which resources will be used. This requires the creation of a complex design center, gradually abandoning traditional design organizations.

The ICP key events matrix defines its organizational structure, but does not clarifies logistics, labor movement, volumes and terms of construction. To form real directive design and estimate documents that define a detailed construction program, it is necessary to supplement the key events matrix with exhaustive information about performance conditions for each key event. Functional blocks of the project should solve this task combined with system designers, i.e. specialized contracting organizations that should specify each graph arc of "project matrix" with a work description, which is performed between an accomplished event and the following one. Work description is carried out according to certain rules that allow operating this information. To do this, an operator card is created, which has its own address, where types of work, terms of execution, list and amount of necessary for work performance resources are attributed. In fact, entire colossal amount of construction, finishing, erection work should be distinguish to elementary operations or to the necessary detalization level. This is a large volume of project work that requires a certain amount of time.

Work acceleration at this stage of documentation development is possible with use of visual programming methods, which do not demand high qualification in programming for technical documentation developers. Methodology of process automation of updating ICP key event matrix reside in considering matrix as a polygon network system - an orgraph, where the vertices of the network are events that determine the state of the project, and the arcs of the orgraph determine project conditions for transition from one state to another, i.e. they are transition operators. In the physical representation, transition is a work or a range of works, which execution allows proceeding from one event to another. Therefore, the transition operator « $\omega_{n}$ " must contain exhaustive information about the work and conditions of its implementation from one event to another. We will write down this requirement in the following form:

$$
\omega_{n}=\sum_{n=1}^{n=m} A_{n} ; \sum_{n=1}^{n=m} R_{n} ; \sum_{n=1}^{n=m} G_{n} ; T_{k p}
$$

Here: $\mathrm{A}$ - work that ensures the achievement of a specific event. $\mathrm{R}$ is a resource, as an execution condition for the corresponding work. $\mathrm{G}$ - labor effort, characterizing each of the works. $\mathrm{T}_{\text {кр }}-$ critical transition time from one event to another. It follows the most important operator property: the transition operator $" \omega_{n}$ » from event "i" to event "j" is equal to the sum of operators of any level of decomposition in the same limits, i.e.:

$$
\omega_{n}=\sum_{n=i}^{n=j} \omega_{n}
$$

This property allows to switch from low-level operators to high-level operators, in other words, to connect operators. 
Figure 4 illustrates this conclusion. A certain level of matrix detalization corresponds to its level of the transition operator, which is fully identified by the transition map. Within transition map all works are listed, which leads the construction system to event 2 from event 1 through their implementation. Transition map contains exhaustive information about labor costs, work executors, machinery use, materials and components supply, timing, i.e. about all work and conditions parameters that are necessary in achieving event. 2. The order of information organization for all maps levels of transition operators is unified, duplicated by the code that is used for machine processing of documentation.

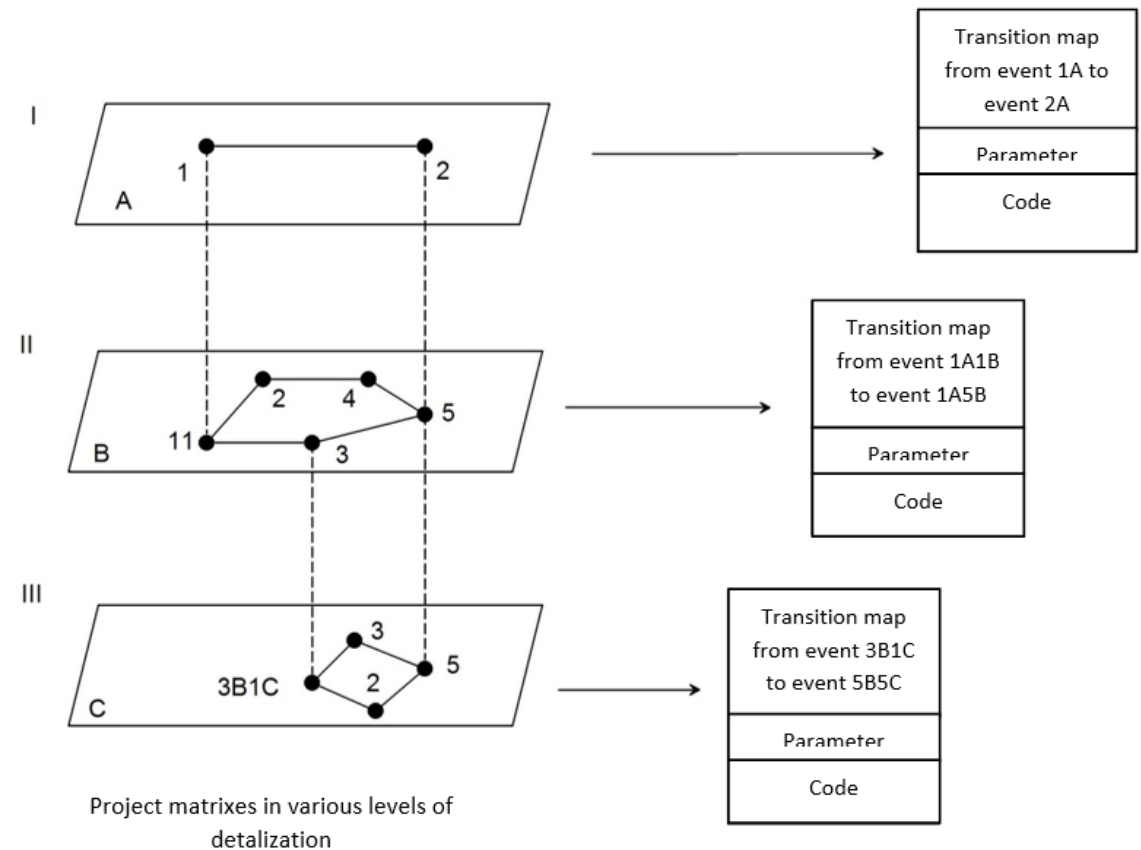

Fig. 4. Maps format from event to event transition, according to the project matrix's detalization level.

It is easy to see that all parameters are the sum of the lower level. This allows to manage works in a parallel scheme with high level of detalization, while designing of the organizational structure.

Appliance of the proposed methodology significantly reduces required time for the investment and construction project implementation of construction complex of industrial and warehouse buildings and structures in the Moscow region.

\section{Conclusions}

Current practice of design and estimate documentation development in establishing a finished product by construction organizations neglects the formation of investment and construction project organizational structure. On customer's level, staff's schedule is approved, the subordination of lower management levels to senior is reflected, what is 
completely insufficient under changing conditions of project participants interconnections in accordance with the current phases and stages of the investment and construction project.

An effective way of forming an investment and construction project's organizational structure is the method of production process analyses that divides it into organizational and technological components. Then it becomes possible to form a corresponding to the current phase of the project organizational structure from production and logical connections of events, works and executors.

The most effective tool of ICP organizational structure formation is the key events matrix. It is a functional network model of the production and logical connections of an events array, which implementation leads to achievement of the target construction goals. Matrix defines the organizational and production relations of project executors and the works sequence to achieve specified events.

In order to form highly effective organizational structures of investment and construction projects on a scientific basis, it is reasonable to create integrated centers of organizational structures' system design as one of the element of construction documentation development.

This work was financially supported by Ministry of Education and Science of the Russian Federation (\#NSh-3492.2018.8).

\section{References}

1. A.A. Morozenko, IJAER, 10(21), 41831-35 (2015)

2. A.A. Morozenko, Refleksno-adaptivnaya model' organizatsionnoy struktury investitsionno-stroitel'nykh proektov (Moscow State University Press, 2013)

3. P. Mao, S. Li, K. Ye, H. Cai, KSCE J. of civil engineering, 1(1), 45-53 (2017)

4. J. Vveinhardt, R. Andriukaitiene, Transformations in business and economics, 15 (2B), 615-629 (2016)

5. P.B. Zhavnerov, A.V. Ginsburg, Natural and Technical Sciences J., 6 (84), 273-275 (2015)

6. A.A. Lapidus, S.A. Feldman, Vestnik MGSU J., 6, 101-106 (2016)

7. A.A. Volkov, S.B. Sborshikov, T.V. Hripko, Vestnik MGSU J., 10, 105-111 (2016)

8. E. Stonkute, J. Vveinhard, Management theory and studies for rural business and infrastructure development, 40 (1), 85-90 (2018)

9. V. Singh, P.M. Singru, J. of Manufacturing Technology, 29(2), 329-349 (2018)

10. A.V. Ginsburg, Industrial and Civil Engineering J., 9, 61-65 (2016) 